\title{
Epidemiology and Seasonal Pattern of Malaria in an Irrigated Area of Eastern Sudan
}

\author{
${ }^{1}$ Yousif El-Safi Himeidan, ${ }^{2}$ Efatih. M. Malik and ${ }^{3}$ Ishag Adam \\ ${ }^{1}$ Medical Entomology Unit, Faculty of Agriculture and Natural Resources \\ University of Kassala, New Halfa, Sudan \\ ${ }^{2}$ Malaria Control Programme, Sudan \\ ${ }^{3}$ University of Khartoum, Faculty of Medicine, Khartoum, Sudan
}

\begin{abstract}
Epidemiological patterns of malaria are widely different; such information can help programs to design interventions relevant to situation. This cohort study investigated the epidemiology of malaria in Dipaira camp, an irrigated area, in eastern Sudan during the period July 2004 to Jun 2005. At baseline, the relevant socio-demographic factors and the monthly malaria parasitological surverys were carried-out. Thirty- six $(4.1 \%)$ out of 860 blood smears were found positive for malaria, 32 were $P$. falciparum and 4 were $P$. vivax. One child (two years old) died due to severe malaria (repeated convulsions). The mean malaria prevalence was 4.2 (95\% confidence interval, 2.84-5.53) per 100 person-months (range, $0.0 \%-11.7 \%$ ), with two peaks in autumn ( 7.5 per 100 person-months) and cool dry seasons (4.6 per 100 person-months). The age and sex were not significantly different between the infected and non- infected groups. Thus, malaria in the area is highly seasonal with prevalence ranging between 0.00 to $11.7 \%$. Efforts to control malaria should be designed to cover the end of the rainy season.
\end{abstract}

Key words: Malaria, epidemiology, hypoendemic, irrigation, Sudan

\section{INTRODUCTION}

Malaria is a major public health problem worldwide, where one million people die every year, 90 $\%$ in sub-Saharan Africa ${ }^{[1,2]}$. Approximately $90 \%$ of this burden is related to environmental factors ${ }^{[3]}$. Several studies documented an increase in malaria incidence as a consequence of irrigation and agricultural development in many countries including Sudan ${ }^{[4-7] .}$

Epidemiological patterns of malaria are widely different; such information can help programs design improved strategic interventions. Malaria causes nearly 7.5-10 million cases and 35,000 deaths every year in Sudan ${ }^{[8]}$. Although the epidemiology of malaria has been subject to extensive studies in other parts of the Sudan ${ }^{[9-14]}$, probably no proper published data exists concerning the epidemiology of malaria in the study area. Recently, high levels of annual vector densities and antimalrial drugs resistance have been reported in New Halfa, an irrigated area in eastern Sudan ${ }^{[15,16]}$. A cross sectional survey conducted during the cool and hot dry seasons in this area suggested that malaria infection is become perennial rather than seasonal as a result of irrigation activities ${ }^{[17]}$. The present study was conducted to investigate the epidemiology and identify the risk factors related to malaria in New Halfa population to guide researchers and decision-makers in targeting intervention efforts. Moreover, the study may provide additional insight into the malaria transmission pattern in the study area.

\section{MATERIALS AND METHODS}

Study area: This study was carried-out at Dibaira camp in the southern part of New Halfa town. New Halfa is the second largest agricultural scheme in Sudan. 168000 ha (400 000 feddans), on the western bank of the Atbara River in eastern Sudan (lat. $15^{\circ} 18^{\circ}-15^{\circ} 21$ $\mathrm{N}$ and long. $\left.35^{\circ} 33^{\circ}-35^{\circ} 37^{\circ} \mathrm{E}\right)$. The scheme has a permanent irrigated system. The climate in the region is semi-arid savannah with three seasons; rainy (JulyOctober) irrigated (November- February) and a dry one (March- June).

New Halfa town is located in the middle of the scheme. P. falciparum is the predominant malaria parasite species and An. arabiensis is the principle vector ${ }^{[15,16]}$. The malaria control operations are irregular with emphasis on larviciding, fogging and sometimes indoor residual spraying.

During the period July 2004 to June 2005, a cohort study was carried- out, where $15 \%$ of the inhabitants (721) were randomly selected. These individuals were interviewed and their relevant sociodemographic characteristics were recorded and clinical examinations were conducted (temperature and spleen).

Monthly surveys were conducted, thick and thin (for species confirmation) blood films were prepared and Geimsa stained to detect the active cases. A slide was considered negative after examination of 200 fields of a thick blood film. The medical team (medical officer and the microscopist) provide the medical

Corresponding Author: Dr. Ishag Adam, P.O. Box 102, Department of Obstetrics and Gynecology, Faculty of Medicine University of Khartoum, Khartoum, Sudan, Tel: +249 912168988, Fax: +249183224799 
services free of charge and they were available every other day in the village. The prevalence of malaria was expressed as a percentage of positive malaria tests per month. Cases of falciparum malaria were treated with artesunate plus pyrimethamine/sulfadoxine (the first line treatment in Sudan, while cases of vivax malaria were treated with chloroquine).

Ethical clearance: The study received ethical clearance from the Research Board of the Faculty of Medicine, University of Khartoum.

Statistical analysis: The data were entered in SPSS, Version 12 (SPSS inc., USA) and double checked before analysis. The difference in prevalences of parasitaemia between different age groups, different seasons and sex were compared using $X^{2}$. The mean age between the infected and non-infected groups was compared using student t-test. P value of less than 0.05 was considered significant.

\section{RESULTS}

Eighty-six individuals were enrolled in the study, of whom $44.2 \%$ were males and $26.7 \%$ were five years old or younger, with a mean age of 16.6 years (range, 0.5- 70 years), table 1. Thirty- six ( $4.1 \%$ ) out of 860 blood smears were found positive, 32 were $P$. falciparum and 4 were $P$. vivax. 22, 13 and one in the rainy, irrigation and dry season respectively (Table 2). One child (two years old) died due to severe malaria (repeated convulsions).

The malaria prevalence ranged from zero to 11.7 per 100 (person-months), with the mean $4.2\left(95 \% \mathrm{CI}_{\text {- }}\right.$ 2.84-5.53) per 100 person-months (Table 2). The peaks were in September (11.7 per 100 person-months), October (9.7 per 100 person-months) and December (8.6 per 100 person-months), gradually decreasing in the cool dry 3 months and disappear during April-July (Fig. 1).

The mean (SD) age was not significantly different between the infected and non-infected groups, 16.5 (15.4) versus 15.0 (14) years. The malaria prevalence was $7.1,4.1$ and 4.1 per 100 person-months in the age groups of less than two, two to nine and above nine years old respectively (Table 2).

The spleen was detected in $0.12 \%$ of the total population and in $0.27 \%$ of the children $2-9$ years old.

\section{DISCUSSION}

The present study was conducted to investigate the epidemiology of malaria among the population living in the pre urban irrigated area of eastern Sudan. The mean malaria prevalence was $4.2\left(95 \% \mathrm{CI}_{-} 2.84,5.53\right)$ per 100 person-months during the study period. This is comparable with the previous mean prevalence (2.48 per 100 person-months), previously reported in the
Table 1: Description of characteristics reported by the study population at baseline

\begin{tabular}{ll}
\hline Variable & Value \\
\hline Age, years (SD) & $16.63 \pm 0.47$ \\
Weight (SD) & $31.57 \pm 0.63$ \\
Male & $44.2 \%$ \\
\hline
\end{tabular}

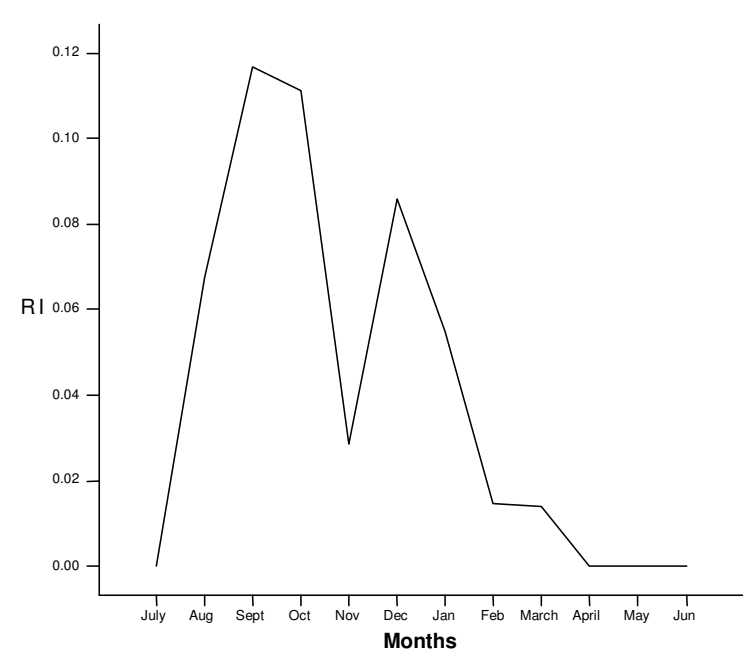

Fig. 1: Seasonality of malaria prevalence of malaria new Halfa town in eastern Sudan during the study period July 04-June 05

short surveys during the cool and hot dry seasons in the area of the study ${ }^{[17]}$.

In the present study there was little $(0.4 \%)$, or no malaria in the period of April-July. The explanation for this finding may be the extremely high daily temperatures (above $40^{\circ} \mathrm{C}$ ) experienced during the dry season. High temperature reduced the survival of adult mosquitoes and perhaps, killed the developing parasites within the vector ${ }^{[18]}$. However, the presence of malaria during April-July may be inevitable in extent of the underlying parasite reservoir in the human host, to maintain the low level of malaria transmission at the beginning of the rainy season. In fact, low submicroscopic malaria has been detected throughout the year including the dry season in eastern Sudan ${ }^{[9,10,11,13,19]}$.

The study showed a seasonal pattern of malaria with two peaks during the rainy and irrigation seasons. The second peak may be explained by the irrigation of wheat during winter. Introduction of irrigation may alter the malaria transmission from seasonal to perennial. This was observed in other African countries ${ }^{[18,20]}$ as well as in the Gezira-Managil irrigated scheme in central Sudan ${ }^{[5]}$. These may result in higher vectorial capacity of $A$. arabiensis as has been observed in irrigated villages in the Rusizi Valley of Burundi, an area of unstable malaria transmission ${ }^{[21]}$.

Evidences of hypoendemicity were found in this area, the mean prevalence was less than $10 \%$, which is the limit for hypoendemicity and low spleen rate among 2-9-years old children did not exceed the limit of $10 \%$ $(0.27 \%)$. 
Am. J. Infectious Dis., 1 (2):75-78, 2005

Table 2:The prevalence of malaria in an urban area of New Halfa town in eastern Sudan by age and season for 86 patients during July 04-June 05

\begin{tabular}{|c|c|c|c|c|c|c|c|c|}
\hline \multirow[t]{2}{*}{ Season } & \multicolumn{2}{|c|}{$<2$ years } & \multicolumn{2}{|c|}{ 2-9 years } & \multicolumn{2}{|c|}{$<9$ years } & \multicolumn{2}{|c|}{ Total } \\
\hline & PR & +ve/tested & PR & +ve/tested & PR & +ve/tested & PR & +ve/tested \\
\hline Rainy & 23.1 & $(3 / 13)$ & 5.6 & $(7 / 124)$ & 7.6 & $(12 / 158)$ & 7.5 & $(22 / 295)$ \\
\hline Irrigation & 0.00 & $(0 / 16)$ & 7.5 & $(7 / 123)$ & 4.2 & $(6 / 142)$ & 4.6 & $(13 / 281)$ \\
\hline Hot dry & 0.00 & $(0 / 13)$ & 0.8 & $(1 / 121)$ & 0.0 & $(0 / 150)$ & 0.4 & $(1 / 284)$ \\
\hline Total & 7.1 & $(3 / 42)$ & 4.1 & $(15 / 368)$ & 4.0 & $(18 / 450)$ & 4.2 & $(36 / 860)$ \\
\hline$P$ value & 0.027 & 0.088 & 0.003 & 0.000 & & & & \\
\hline
\end{tabular}

Similarly, in Brazilian hypoendemic Amazon State, prevalences between 0.5 and $4.2 \%$ have been documented and spleen rate of less than $1 \%$ was also always detected among this age group ${ }^{[22,23]}$.

In this study age and sex were not risk factors for malaria, this goes with the previous observations in Sudan $^{[9,23]}$ as well as in the neighbour Eritrea ${ }^{[24]}$.

A two years old child died because of severe malaria (repeated convulsions). Different manifestations and mortality of severe falciparum malaria were reported among Sudanese patients ${ }^{[25-27]}$.

Thus, preventive measures should be directed to the populations as the hole irrespective to their age or sex, but mainly in the rainy and post rainy seasons.

\section{ACKNOWLEDGMENTS}

The authors wish to thanks all the patients for their co-operation and Mr Abdalla Ahmmed Hafazalla for his excellent technical work.

\section{REFERENCES}

1. Breman, J.G., 2001. The ears of the hippopotamus: Manifestations, determinants and estimates of the malaria burden. Am. J. Trop. Med. Hyg., 64 (Suppl): 1-11.

2. WHO, 2004. The World Health Report 2004 Changing History. Geneva: World Health Organization.

3. WHO, 1997. Health and Environment in Sustainable Development. Geneva: World Health Organization.

4. Pant, C.P. and N. Gratz, 1979. Malaria and agricultural development. Outlook Agric., 10: 111115.

5. El Gaddal, A.A, A.A.M. Haridi, F.T. Hassan and H. Hussein, 1985. Malaria control in the GeziraManagil irrigated scheme of the Sudan. J. Trop. Med. Hyg., 88: 153-159.

6. Service, M.W., 1991. Agricultural development and arthropodborne diseases: A review. Rev Saude Publica, 25: 165-178.

7. Ijumba, J.N., F.C. Shenton, S.E. Clarke, F.W. Mosha and S.W. Lindsay, 2002. Irrigated crop production is associated with less malaria than traditional agricultural practices in Tanzania. Trans. R. Soc. Trop. Med. Hyg., 96: 476-480.
8. Malik, E.M. and O.K. Saed, 2004. Malaria in Sudan: Past, present and the future. Gezira J.H. Sc., 1(suppl): 47-51.

9. Roper, C., I.M. Elhassan, L. Hviid, H. Giha, W. Richardson, H. Babiker, G.M. Satti, T.G. Theander and D.E. Arnot, 1996. Detection of very low-level Plasmodium falciparum infections using the nested polymerase chain reaction and a reassessment of the epidemiology of unstable malaria in Sudan. Am. J. Trop. Med. Hyg., 54: 325-331.

10. Roper, C., W. Richardson, I.M. Elhassan, L. Hviid, H. Giha, G.M. Satti, T.G. Theanderand D.E. Arnot, 1998. Seasonal changes in the Plasmodium falciparum population in individuals and their relationship to clinical malaria: A longitudinal study in a Sudanese village. Parasitology, 116:501510.

11. Babiker, H.A., 1998. Unstable malaria in Sudan: The influence of the dry season. Plasmodium falciparum population in the unstable malaria area of eastern Sudan is stable and genetically complex. Trans. R. Soc. Trop. Med. Hyg., 92: 585-589.

12. Theander, T.G., 1998. Unstable malaria in Sudan: the influence of the dry season. Malaria in areas of unstable and seasonal transmission. Lessons from Daraweesh. Trans. R. Soc. Trop. Med. Hyg., 92: 589-592.

13. Hamad, A.A., I.M. El Hassan, A.A. El Khalifa, G.I. Ahmed, S.A. Abdelrahim, T.G. Theander and D.E. Arnot, 2000. Chronic Plasmodium falciparum infections in an area of low intensity malaria transmission in the Sudan. Parasitology, 120: 44756.

14. Hamad, A.A., A.D. Nugud, D.E. Arnot, H.A. Giha and A.M. Abdel-Muhsin, 2002. A marked seasonality of malaria transmission in two rural sites in eastern Sudan. Acta Tropica, 83: 71- 82.

15. Himeidan, YE., M.Y. Dukeen, E. El-Rayah and I. Adam, 2004. Anopheles arabeinsis: Abundance and insecticide resistance in irrigated area of eastern Sudan. East Mediterr. Health J., 10: 167174.

16. Adam, I, M.E. Osman, G. Elghzali, G.I. Ahmed, L.L. Gustafssons and M.I. Elbashir, 2004. Efficacies of chloroquine, sulfadoxinepyrimethamine and quinine in the treatment of uncomplicated, Plasmodium falciparum malaria in eastern Sudan. Ann. Trop. Med. Parasitol., 98: 661-666. 
17. Himeidan, Y.E., M.I. Elbashir, E. El-Rayah and I. Adam. Epidemiology of malaria in an irrigated area in the eastern Sudan. East Mediterr Health J. (In Press).

18. Ijumba, J.N. and S.W. Lindsay, 2001. Impact of irrigation on malaria in Africa: Paddies paradox. Med. Vet. Entomol., 15: 1-11

19. Adam, I., I.E. A-Elbasit, I. Salih and M.I. Elbashir, 2005. Submicroscopic Plasmodium falciparum infections during pregnancy, in an area of Sudan with a low intensity of malaria transmission. Ann. Trop. Med. Parasitol., 99: 339-344.

20. Sow, S., S.J. de Vlas, D. Engels and B. Gryseels, 2002. Alter-related disease patterns before and after the construction of the Diama dam in northern Senegal. Ann. Trop. Med. Parasitol., 96: 575-586.

21. Coosemans, M., V. Petrarca, M. Barutwanayo and M. Coluzzi, 1989. Species of the Anopheles gambiae complex and chromosomal polymorphism in a rice-growing area of the Rusizi Valley (Republic of Burundi). Parassitologia, 31: 113-122.

22. Camargo, L.M., M.U. Ferreira, H. Krieger, E.P. De Camargo and L.P. Da Silva, 1994. Unstable hypoendemic malaria in Rondonia (western Amazon region, Brazil): Epidemic outbreaks and work-associated incidence in an agro-industrial rural settlement. Am. J. Trop. Med. Hyg., 51: 16-22.
23. El Sayed, B.B., D.E. Arnot, M.M. Mukhtar, O.Z. Baraka, A.A. Dafalla, D.E.A. Elnaiem and A.H.D. Nugud, 2000. A study of the urban malaria transmission problem in Khartoum. Acta Trop., 75: 163-171.

24. Sintasath, D.M., 2005. Malaria prevalence and associated risk factors in Eritrea. Am. J. Trop. Med. Hyg., 72: 682-687.

25. Adam, I., H. Idris, A.A. Mohamed-Ali, I.A. Alelbasit and M.I. Elbashir, 2000. Quinine versus artemether in the treatment of severe falciparum malaria in Sudanese children. The East Afr. Medl. J., 79: 621-625.

26. Adam, I. and M.I. Elbashir, 2004. Maternal death due to severe pulmonary edema caused by falciparum malaria: Case report. East Mediterr. Health J., 10: 685-688.

27. Giha, H.A., G. ELGhazali, T.M. Elhassan, I. Eltayib, E.M. Eltahir, O.M. Baraka, M.M. Khier, I. Adam, M.T. Blomberg, T.G. Theander and M.I. Elbashir, 2005. Clinical pattern of severe P. falciparum malaria in Sudan in an area characterized by seasonal and unstable malaria transmission. Trans. R. Soc. Trop. Med. Hyg., 99: 243-251. 